29. Seitenstück zum Gaußschen Lemma . . . . . . . . . . . . . . . . . . . . 84

30. Die Charaktere von 2-Potenzordnung mit zusammengesetztem Führer . . . . . . 87

31. Die Charaktere mit ungeradem Primzahlpotenzführer . . . . . . . . . . . . . 90

32. Die Charaktere mit 2-Potenzführer . . . . . . . . . . . . . . . . . . . 93

33. Direkter Ganzzahligkeitsbeweis . . . . . . . . . . . . . . . . . . . . 95

34. Der Satz von Weber und ein Seitenstück dazu . . . . . . . . . . . . . . . 101

35. Bemerkungen über den Geschlechterfaktor . . . . . . . . . . . . . . . . . . 114

36. T'eilbarkeit durch die Relativklassenzahl eines Teilkörpers . . . . . . . . . . . 115

37. Imaginäre abelsche Zahlkörper mit ungerader Klassenzahl ． . . . . . . . . . . 118

38. Imaginäre zyklische Zahlkörper mit ungerader Klassenzahl . . . . . . . . . . . 123

Anhang: Relativklassenzahltafeln . . . . . . . . . . . . . . . . . . . . . 133

Tafel I: Die Relativklassenzahlbeiträge der Charaktere

1. Primzahlpotenzführer . . . . . . . . . . . . . . . . . . . . . . . . . . 139

2. Zusammengesetzte Führer . . . . . . . . . . . . . . . . . . . . . . . . . 140

Hilfstafel: Die Werte der Grundcharaktere . . . . . . . . . . . . . . . . . . 142

Tafel II: Die Relativklassenzahlen

1. Primzahlpotenzführer. . . . . . . . . . . . . . . . . . . . . . . . . . . . 148

2. Zusammengesetzte Führer . . . . . . . . . . . . . . . . . . . . . . . 156

Hilfstafel: Die Werte des Einheitenindex . . . . . . . . . . . . . . . . 186

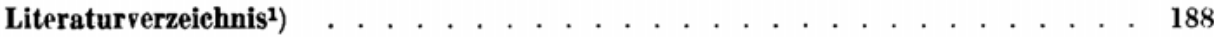

\title{
Verzeichnis der Sätze
}

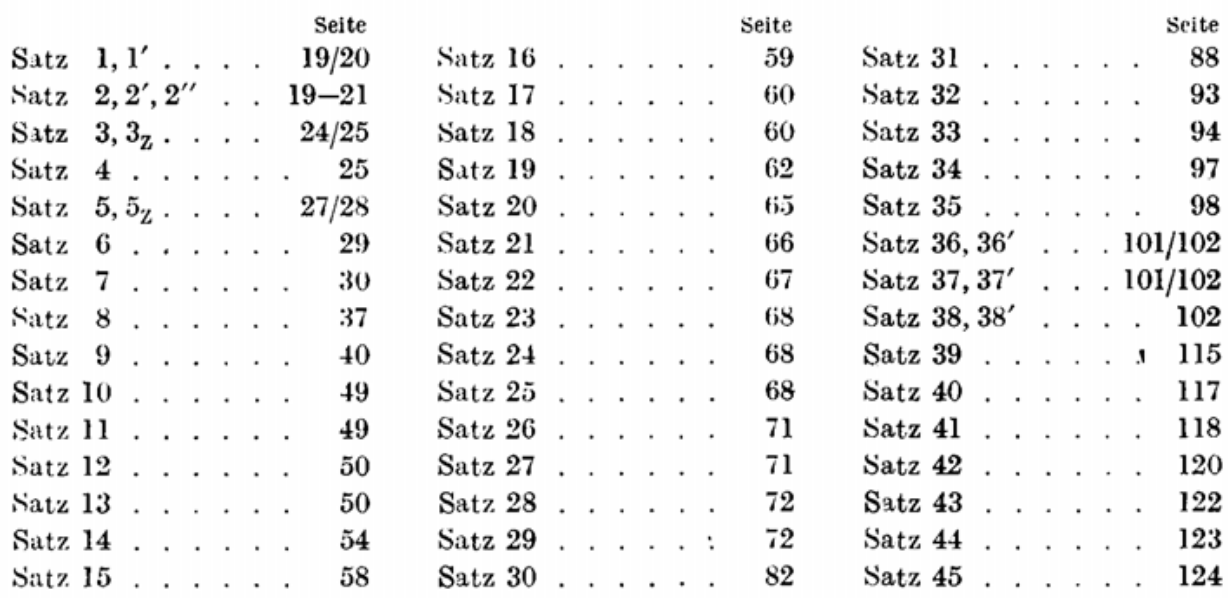

1) Die in diesem Literaturverzeichnis angeführten Arbeiten werden im Text durch Angabe der entsprechenden Ziffern in eckigen Klammern hinter den Autorennamen zitiert. 